\title{
Risk Management with Options and Futures under Liquidity Risk*
}

\author{
Axel F.A. Adam-Müller ${ }^{\dagger}$ \\ University of Trier \\ FB IV - BWL \\ D - 54286 Trier, Germany \\ Tel.: +49-651-2012725, Fax: +49-651-2013841 \\ email: adam-mueller@uni-trier.de \\ Argyro Panaretou \\ Lancaster University Management School \\ Department of Accounting and Finance \\ Lancaster LA1 4YX, United Kingdom \\ Tel.: +44-1524-593637, Fax: +44-1524-847321 \\ email: a.panaretou@lancaster.ac.uk
}

\begin{abstract}
Futures hedging creates liquidity risk through marking to market. Liquidity risk matters if interim losses on a futures position have to be financed at a markup over the risk-free rate. This paper analyzes the optimal risk management and production decisions of a firm facing joint price and liquidity risk. It provides a rationale for the use options on futures in imperfect capital markets. If liquidity risk materializes, the firm sells options on futures in order to partly cover this liquidity need. It is shown that liquidity risk reduces the optimal hedge ratio and that options are not normally used before a liquidity need actually arises.
\end{abstract}

Keywords: liquidity risk, risk management, options on futures, futures

JEL classification: G11; D81

${ }^{*}$ We would like to thank Bart Lambrecht, Grzegorz Pawlina, Siegfried Trautmann, Piet Sercu and seminar participants at Leuven and Mainz for helpful discussions and comments. Of course, all remaining errors are our responsibility.

${ }^{\dagger}$ Corresponding author. 


\section{Risk Management with Options and Futures under Liquidity Risk}

Futures hedging creates liquidity risk through marking to market. Liquidity risk matters if interim losses on a futures position have to be financed at a markup over the risk-free rate. This paper analyzes the optimal risk management and production decisions of a firm facing joint price and liquidity risk. It provides a rationale for the use options on futures in imperfect capital markets. If liquidity risk materializes, the firm sells options on futures in order to partly cover this liquidity need. It is shown that liquidity risk reduces the optimal hedge ratio and that options are not normally used before a liquidity need actually arises.

Keywords: liquidity risk, risk management, options on futures, futures

JEL classification: G11; D81 


\section{Introduction}

Consider a producer exposed to output price risk. If price risk can be managed with futures contracts, a full hedge ensures that the producer's financial position at the hedging horizon is almost risk-free. However, this is only true if the producing firm can always accommodate the liquidity needs that may arise from the marking to market of the futures position. Depending on the development of the futures price over time, marking to market may lead to interim cash inflows and/or cash outflows prior to the hedging horizon. Suppose that the producing firm faces a liquidity constraint in the sense that there is no free cash at hand. If the original futures position generates an interim loss, the producer will have to raise additional cash in order to maintain the position. Usually, the borrowing rate is higher than the interest rate applicable to any excess cash that might be generated by marking to market. Hence, the producer faces liquidity risk: If the futures position creates an intermediate loss, additional cash has to be raised which is costly. The producer will anticipate the possibility of additional liquidity needs arising from the futures position when deciding about the optimal hedging position in futures contracts. If the producer can also trade options on futures, he might use these options to manage the liquidity risk borne by the futures position. This will also affect the size of the optimal futures position and the optimal production decision.

This paper analyzes the impact of joint price risk and liquidity risk on optimal output and on the optimal positions in futures and in options on futures taken by a risk-averse producing firm. Hedging price risk with futures contracts creates liquidity risk through marking to market. Liquidity risks can be significant ${ }^{1}$ : In the

\footnotetext{
${ }^{1}$ See Committee on Payments and Settlement Systems (1998). A prominent example for the significance of liquidity risks is the case of Metallgesellschaft AG (MG). In 1993, a subsidiary (Metallgesellschaft Refining \& Marketing Inc.) took short positions in long-dated oil forward commitments and long positions in oil futures contracts. A few months later, significant margin calls from the futures positions created substantial liquidity needs that ultimately led to a severe crisis of MG: In late 1993, the futures positions had to be closed causing a loss of more than a billion
} 
extreme case, the entire derivatives position has to be liquidated. In less extreme cases, there is the opportunity cost of quickly raised cash. The firm modeled here faces a liquidity constraint in the following sense: There is no free cash available from within the firm, but the firm can borrow additional funds at a firm-specific borrowing rate. In addition, the firm can trade options on futures. As the liquidity risk is an asymmetric risk - it only materializes if the futures position creates an interim cash outflow - options might be used to alleviate the impact of liquidity risk on the firm's financial position.

The paper employs a two-period framework where futures contracts maturing at the end of the second period are traded at the beginning of each period. In addition, one-period options on futures are traded at the beginning of every period. The analytical results are as follows: If the derivatives position entered into in the first period generates a loss by the end of this period, the firm will optimally sell fairly priced call options on futures in order to generate funds to cover (part of) this loss. $^{2}$ As doing so changes the firm's exposure to price risk, the futures position is adjusted as well. If there is no loss by the end of the first period, no options position will be taken and the firm fully hedges with futures contracts over the second period. The numerical results show that the firm under-hedges in the first period as a result of the existence of the liquidity constraint. They also indicate that options are not used in the first period.

The impact of liquidity risk on futures hedging has been studied by Lien (2003), Lien and Li (2003) Wong (2004a), Wong (2004b) and Wong and Xu (2006). Lien (2003) shows that the initial futures position depends upon the firm's ability to cope with losses arising from marking to market. Wong (2004a) proves that the optimal US Dollars as banks and major shareholders were not prepared to provide additional liquidity; the CEO was replaced. See Culp and Miller (1995) and Mello and Parsons (1995), among others.

${ }^{2}$ Hence, the paper offers a justification of the hedging role of options on futures. Another argument is provided by Lien and Wong (2002) who show that options on futures will be used if there are multiple delivery specifications (delivery options) embedded in futures contracts. 
futures hedge is an underhedge if the firm is prudent in the sense of Kimball (1990; 1993). He also shows that production decreases if liquidity risk is introduced. Wong (2004b) analyzes the hedging problem of a firm that can trade futures contracts with two different maturities. All these papers focus on a particular type of liquidity risk where the firm has to liquidate the entire futures position if the interim cash outflow exceeds an exogenously given threshold. ${ }^{3}$ This assumption is isomorphic to assuming that the cost of covering an interim loss caused by marking to market equals the risk-free rate for an amount up to the level of the threshold and then effectively jumps to infinity such that raising external cash beyond the threshold is ruled out. In contrast, our model follows Korn (2004) by assuming that there is no such borrowing threshold but that all borrowing has to be done at a firm-specific borrowing rate depending on the firm's credit standing. It seems more appropriate for most firms to assume that there is no such extreme jump in the cost of raising additional cash. As a consequence, the firm is able to maintain its futures position even if the interim losses are significant.

The two papers that are closest to ours are Korn (2004) and Wong and Xu (2006). Korn (2004) analyzes optimal forward hedging. His model is based on the assumption that the firm will have to provide cash as collateral if the forward position has a negative market value prior to the hedging horizon. Unlike our model, an interim cash inflow from the forward position is not permitted in Korn's (2004) model. More importantly, Korn (2004) does not allow for options whereas our model does. To our knowledge, Wong and Xu's (2006) model is the first to incorporate options (on the firm's output) into the futures hedging problem. In their model, however, the firm has to liquidate any derivatives position if the interim loss exceeds an exogenously given threshold. Our model, in contrast, uses a more flexible approach by assuming

\footnotetext{
${ }^{3}$ The same applies to Deep's (2002) model. Zhoo (1998) analyzes the implications of a closely related assumption on futures pricing.
} 
a firm-specific borrowing rate that allows the firm to borrow larger amounts, though always at a cost. In sum, the present paper's contribution is to combine the joint availability of options and futures contracts with the more flexible, less extreme approach to model liquidity risk that does not require an exogenously fixed borrowing threshold.

The paper is organized as follows: Section 2 presents the model. As a benchmark for comparison, Section 3 characterizes the optimal decisions in the absence of liquidity risk. The main results of the paper are presented in Sections 4 and 5: The optimal decisions taken in the second period are characterized analytically in Section 4. Numerical results including the decisions taken in the first period are presented in Section 5. Section 6 concludes. All proofs are relegated to the Appendix.

\section{The model}

The firm under consideration produces a commodity that is sold at a random spot price at a later date. Commodity price risk introduces uncertainty into the firm's cash flows. However, price risk can be managed with futures contracts and with options on these futures contracts. The firm's optimal hedging decisions are analyzed in a simple dynamic setting with three dates, $t=0,1,2$. Futures contracts are traded at $t=0$ and $t=1$ and mature at $t=2$. One-period call options on futures are traded at $t=0$ and $t=1$. Positions in futures and options on futures will generally lead to cash flows at all three dates.

The firm is assumed to operate under a liquidity constraint: There is no free cash available in the firm. As a result, any net cash outflow forces the firm to borrow at an interest rate above the risk-free rate. ${ }^{4}$ The markup over the risk-free rate is

\footnotetext{
${ }^{4}$ This implies that any gain on the spot position cannot be accessed directly or indirectly through borrowing until $t=2$. See Lien (2003) for a closely related assumption.
} 
denoted by $\tau \geq 0 . \quad \tau$ is time-invariant and independent of the value of the firm's position in the underlying commodity and its derivatives positions. Cash inflows at $t=0$ and $t=1$ will be invested until the next date at the risk-free rate. For simplicity, the risk-free rate is set equal to zero.

In the following, we describe the firm's decisions and the resulting cash flows in detail. At $t=0$, three decisions have to be made. The first is on the amount to be produced, denoted $Q$. The cost function $C(Q)$ satisfies $C(0) \geq 0, C^{\prime}(Q)>0$ and $C^{\prime \prime}(Q)>0$. Costs $C(Q)$ are accrued to $t=2$. At $t=2$, the firm's output is sold in a competitive market at a price $\tilde{S}$ that is risky. ${ }^{5} \tilde{S}$ is distributed over support $[\underline{S}, \bar{S}]$. Producing an amount $Q$ and selling it at $t=2$ leads to a cash flow of $\tilde{S} Q-C(Q)$ at that date. Other activities of the firm are assumed to generate a deterministic cash inflow of $I$ at $t=2$.

The second decision is on the size of futures position. This position is denoted by $X_{0}$ where $X_{0}>0$ indicates a forward sale and $X_{0}<0$ a forward purchase. Futures contracts mature at $t=2$ and are marked to market at $t=1 . f_{t}$ is the futures price at time $t$. $\tilde{f}_{1}$ is distributed over support $\left[\underline{f_{1}}, \overline{f_{1}}\right]$. The convergence property of futures prices implies $\tilde{f}_{2}=\tilde{S}$. The futures market is assumed to be unbiased in each period such that $f_{t}=\mathrm{E}_{t}\left[\tilde{f}_{t+1}\right]$ for $t=0,1$ where $\mathrm{E}_{t}[\cdot]$ denotes the expected value given the information at time $t .^{6}$ Marking to market at $t=1$ generates a cash flow of $X_{0}\left[f_{0}-\tilde{f}_{1}\right]{ }^{7}$ At $t=2$, the futures position expires and leads to a cash flow of $X_{0}\left[f_{1}-\tilde{S}\right]$.

\footnotetext{
${ }^{5}$ Henceforth, random variables have a tilde $(\sim)$, their realizations do not. A star $\left(^{*}\right)$ indicates an optimized level.

${ }^{6}$ See Wong and $\mathrm{Xu}(2006)$ for a similar assumption.

${ }^{7}$ As Korn (2004) analyzes forward hedging in conjunction with the provision of collateral, his model only takes cash outflows into consideration but cannot capture cash inflows at $t=1$. The model presented here, however, can analyze both types of cash flows.
} 
The third decision to be made at $t=0$ relates to the position in call options on futures, denoted $Z_{0} \cdot{ }^{8}$ At $t=0$, there are call options available with maturity $t=1$ and strike price $K_{0}$ at a premium of $P_{0}$. Suppose that $K_{0}=\mathrm{E}_{0}\left[\tilde{f}_{1}\right] .{ }^{9}$ The unbiasedness of the futures market implies $K_{0}=f_{0}$. If $Z_{0}>0$, the firm purchases call options. $Z_{0}<0$ denotes a short options position. Trading $Z_{0}$ call options at $t=0$ generates an immediate cash flow of $-Z_{0} P_{0}$. If the holder exercises these call options at time $t=1$, he receives a long futures position with maturity $t=2$ at the then prevailing futures price $f_{1}$. (This futures position has a market value of zero at date $t=1$. For simplicity, we assume that this futures position is immediately offset in the market. Hence, this futures position will be no longer dealt with.) In addition, he receives a cash payment of $\left(f_{1}-K_{0}\right)$ upon exercise of the option. Hence, options traded at $t=0$ generate a cash flow of $Z_{0} \max \left[\tilde{f}_{1}-K_{0}, 0\right]$ at $t=1$.

At date $t=1$, two decisions have to be made. The first is whether to adjust the futures position. This adjustment is denoted by $X_{1} \cdot X_{1}>0$ denotes a short futures position, acquired at the prevailing futures price $f_{1}$. $\left(X_{1}<0\right.$ denotes a long futures position.) At expiration of the futures contracts at $t=2$, this adjustment leads to a cash flow of $X_{1}\left[f_{1}-\tilde{S}\right]$.

The second decision to be made at $t=1$ is on the size of the position in call options maturing at $t=2$. The premium of these options is $P_{1}$, their strike price is $K_{1}=\mathrm{E}_{1}[\tilde{S}]$. The unbiasedness of the futures market in the second period implies $K_{1}=f_{1}=\mathrm{E}_{1}\left[\tilde{f}_{2}\right]=\mathrm{E}_{1}[\tilde{S}] .{ }^{10} Z_{1}>0$ denotes a long position in call options, $Z_{1}<0$ a short position. Taking an options position at $t=1$ generates an immediate cash flow of $-Z_{1} P_{1}$ and a cash flow of $Z_{1} \max \left[\tilde{S}-f_{1}, 0\right]$ at $t=2$.

\footnotetext{
${ }^{8}$ Due to put call parity, a put option on futures can be replicated using call options on futures and futures contracts. See Hull (2006, Ch. 14), for example.

${ }^{9}$ See Chang and Wong (2003) for an assumption made in the same spirit.

${ }^{10}$ Due to convergence property of futures prices, it does not matter whether the options under consideration here are options on futures contracts maturing at $t=2$ or options on the underlying itself. For any such options to make economic sense, we have to have $\underline{S}<f_{1}<\bar{S}$.
} 
In order to focus on the hedging role of options and futures contracts, the markets for these derivatives are assumed to be jointly unbiased. ${ }^{11}$ Hence, option prices are given by $P_{t}=\mathrm{E}_{t}\left[\max \left(\tilde{f}_{t+1}-f_{t}, 0\right)\right]$ and futures prices are given by $f_{t}=\mathrm{E}_{t}\left[\tilde{f}_{t+1}\right]$ for $t=0,1$. In addition, it is assumed that the futures market is intertemporally unbiased such that $f_{0}=\mathrm{E}_{0}[\tilde{S}]$. In biased markets, there will be speculative positions in options and/or futures contracts which could be easily incorporated into the model. However, the purpose of this paper is not to impose an ad hoc pricing theory but to concentrate on the hedging role of futures and options.

The remainder of this section focuses on the cash flows resulting from these decisions. As the firm faces a liquidity constraint, negative cash flows at $t=0$ and $t=1$ will have to be financed until the following date. At $t=0$, the total cash flow amounts to $\phi_{0}=-P_{0} Z_{0}$. If $\phi_{0}$ is positive, the firm will invest the excess cash at the risk-free rate until $t=1$, generating a cash inflow of $\phi_{0}$ at $t=1$. However, if $\phi_{0}$ is negative, the liquidity constraint is binding such that the firm will have to borrow at the markup $\tau$ and repay $(1+\tau) \phi_{0}$ at $t=1$.

At $t=1$, there are cash flows from the marking to market of the existing futures position $X_{0}$, from the settlement of the existing options position $Z_{0}$, from any new position in options $Z_{1}$, and from $\phi_{0}$. Their sum is given by ${ }^{12}$

$$
\tilde{\phi}_{1}=X_{0}\left(f_{0}-\tilde{f}_{1}\right)+Z_{0} \max \left[\tilde{f}_{1}-f_{0}, 0\right]-\tilde{P}_{1} Z_{1}-P_{0} Z_{0}+\min \left[\phi_{0}, 0\right] \tau
$$

Any excess cash $\left(\phi_{1}>0\right)$ will be invested until $t=2$. If $\phi_{1}<0$, the firm is liquidity constrained at $t=1$ in which case it has to borrow until $t=2$ and repay $(1+\tau) \phi_{1}$ at that date.

\footnotetext{
${ }^{11}$ Benninga and Oosterhof (2004) show that the representative agent does not necessarily have to be risk neutral in order to ensure that the futures market is unbiased.

${ }^{12}$ Given the information at $t=0$, the futures price as well as the premium and the strike price of the second-period options are random variables, $\tilde{f}_{1}$ and $\tilde{P}_{1}$.
} 
At $t=2$, there are cash flows from producing and selling the output, from the firm's other activities, from the settlement of the options position $Z_{1}$ and the futures positions $X_{0}$ and $X_{1}$ as well as from $\phi_{1}$. They add up to

$$
\begin{aligned}
\tilde{\phi}_{2}= & \tilde{S} Q-C(Q)+I+\left(X_{0}+X_{1}\right)\left(\tilde{f}_{1}-\tilde{S}\right)+Z_{1} \max \left[\tilde{S}-\tilde{f}_{1}, 0\right] \\
& +X_{0}\left(f_{0}-\tilde{f}_{1}\right)+Z_{0} \max \left[\tilde{f}_{1}-f_{0}, 0\right] \\
& -P_{0} Z_{0}-\tilde{P}_{1} Z_{1}+\min \left[\phi_{0}, 0\right] \tau+\min \left[\tilde{\phi}_{1}, 0\right] \tau
\end{aligned}
$$

Substituting $\phi_{0}$ and $\phi_{1}$ into $\phi_{2}$ results in the firm's total cash flow at date $t=2$, given the information at $t=0$, denoted $W\left(\tilde{S}, \tilde{f}_{1}, \tilde{P}_{1}\right)$ :

$$
\begin{aligned}
& W\left(\tilde{S}, \tilde{f}_{1}, \tilde{P}_{1}\right)=\tilde{S} Q-C(Q)+I+\left(X_{0}+X_{1}\right)\left(\tilde{f}_{1}-\tilde{S}\right)+X_{0}\left(f_{0}-\tilde{f}_{1}\right) \\
& \quad+Z_{0} \max \left[\tilde{f}_{1}-f_{0}, 0\right]-P_{0} Z_{0}+Z_{1} \max \left[\tilde{S}-\tilde{f}_{1}, 0\right]-\tilde{P}_{1} Z_{1} \\
& +\tau \min \left[-P_{0} Z_{0}, 0\right]+\tau \min \left[X_{0}\left(f_{0}-\tilde{f}_{1}\right)+Z_{0} \max \left[\tilde{f}_{1}-f_{0}, 0\right]\right. \\
& \left.\quad-\tilde{P}_{1} Z_{1}-P_{0} Z_{0}+\tau \min \left[-P_{0} Z_{0}, 0\right], 0\right]
\end{aligned}
$$

The decision maker is assumed to have preferences over the distribution of $\tilde{W}$ that can be summarized by a utility function $U(W)$ that is at least twice continuously differentiable and exhibits risk aversion, $U^{\prime}(W)>0, U^{\prime \prime}(W)<0$. In addition, $\lim _{W \rightarrow 0} U^{\prime}(W) \rightarrow+\infty$ and $\lim _{W \rightarrow+\infty} U^{\prime}(W) \rightarrow 0$. Hence, the decision problem is given by

$$
\max _{Q, X_{0}, X_{1}\left(f_{1}\right), Z_{0}, Z_{1}\left(f_{1}\right)} \mathrm{E}_{0}\left[U\left(W\left(\tilde{S}, \tilde{f}_{1}, \tilde{P}_{1}\right)\right)\right] \quad \text { s.t. }(3) .
$$

Futures contracts are often written on underlyings where the production process is subject to quantity risk, for example in agriculture. As quantity risk is not the focus of this paper it might seem more appropriate to model a processor's decision problem where quantity risk is usually very small. However, this paper models a producer in order to keep the analysis in line and therefore comparable with the literature. 


\section{Optimal decisions in the absence of liquidity risk}

This paper focuses on the impact of a liquidity constraint on optimal decisions. In order to establish a benchmark for comparison, this section analyzes the firm's decisions in the absence of such a constraint. Hence, we assume that $\tau=0$ throughout this section. As follows directly from (3), the firm's cash flow at $t=2$ in this benchmark case is given by

$$
\begin{aligned}
\tilde{W}^{b}= & \tilde{S} Q^{b}-C\left(Q^{b}\right)+I+\left(X_{0}^{b}+X_{1}^{b}\right)\left(\tilde{f}_{1}-\tilde{S}\right)+X_{0}^{b}\left(f_{0}-\tilde{f}_{1}\right) \\
& +Z_{0}^{b} \max \left[\tilde{f}_{1}-f_{0}, 0\right]-P_{0} Z_{0}^{b}+Z_{1}^{b} \max \left[\tilde{S}-\tilde{f}_{1}, 0\right]-\tilde{P}_{1} Z_{1}^{b} .
\end{aligned}
$$

In the absence of a liquidity constraint, any cash outflow from marking to market can be met without incurring additional cost. Hence, marking to market has no impact at all (as the risk-free interest rate is zero) and Holthausen's (1979) results for the related single-period problem still apply in the multi-period setting of the current model: The firm fully hedges at $t=0$ and production is determined independently of the (joint) distribution of the risk(s) faced and the degree of risk aversion of the decision maker (separation theorem). There is no role for options on futures, even in the multi-period setting. ${ }^{13}$ The futures position is not adjusted at $t=1$. This is summarized in the following statement.

Proposition 1 Assume that there is no liquidity constraint. The firm fully hedges its output with futures contracts at $t=0, X_{0}^{b *}=Q^{b *}$. The futures position is not adjusted at $t=1, X_{1}^{b *}=0$. No position in options is taken, $Z_{0}^{b *}=Z_{1}^{b *}=0$. The separation theorem holds.

\footnotetext{
${ }^{13}$ Battermann et al. (2000) derive a similar result for the single-period case. In a multi-period framework, Lapan et al. (1991) show that there is no hedging role for options, given a certain type of basis risk. Unlike the present paper, theirs focuses on options on the spot and does not allow for marking to market.
} 


\section{The impact of liquidity risk}

We now assume that the firm is liquidity constrained such that any liquidity needs have to be covered by borrowing at a markup over the risk-free rate of $\tau$. Excess cash is invested at the risk-free rate of zero. The firm's optimization problem has to be solved recursively. While the optimal decisions taken at $t=1$ can be characterized without imposing any further assumptions, the decisions at $t=0$ can not. Therefore, numerical solutions are presented in Section 5.

Consider the second-period problem where the decisions on $Q, X_{0}$ and $Z_{0}$ have already been made. At $t=1$, the realizations of the random variables $\tilde{f}_{1}$ and $\tilde{P}_{1}$ are known. Against this background, the firm solves

$$
\max _{X_{1}\left(f_{1}\right), Z_{1}\left(f_{1}\right)} \mathrm{E}_{1}\left[U\left(W\left(\tilde{S}, f_{1}, P_{1}\right)\right)\right] \quad \text { s.t. }(3) .
$$

In order to simplify the notation, let $\kappa=\phi_{1}+P_{1} Z_{1}=X_{0}\left(f_{0}-f_{1}\right)+Z_{0} \max \left[f_{1}-\right.$ $\left.f_{0}, 0\right]-P_{0} Z_{0}+\tau \min \left[-P_{0} Z_{0}, 0\right]$ denote the firm's cash flow at $t=1$, excluding the cash flow generated from any options position taken at that date.

If $\kappa<0$, the firm's optimal decisions on $X_{0}$ and $Z_{0}$, combined with the realization

of the futures price $\tilde{f}_{1}$, generate a cash outflow. Hence, the liquidity constraint is binding. As (1) shows, any other cash flow at $t=1$ can only be generated by taking a position in options on futures. If no options position is taken, the firm has to borrow $|\kappa|$ until $t=2$. The firm can reduce the size of the loan by shortening options. Intuitively, we would expect options on futures to play a role whenever $\kappa<0$.

Alternatively, if $\kappa \geq 0$, the decisions taken at $t=0$ and the realization of $\tilde{f}_{1}$ do not create a cash outflow. In other words, the liquidity constraint is not binding. Intuition suggests that the firm's optimal decisions at $t=1$ are the same as in the 
absence of liquidity risk (Proposition 1). In particular, we expect no hedging role for options, $Z_{1}^{*}=0$, if the liquidity constraint is not binding. The following result confirms both presumptions.

Proposition 2 If the liquidity constraint in the second period is binding, $\kappa<0$, the firm optimally sells options on futures, $Z_{1}^{*}<0$, and chooses an underhedging position in futures over the second period, $X_{1}^{*}<Q^{*}-X_{0}^{*}$. The optimal derivatives position ensures that $\partial W^{*} / \partial S>0$ for $S \in\left[\underline{S}, f_{1}\right]$ and $\partial W^{*} / \partial S<0$ for $S \in\left(f_{1}, \bar{S}\right]$.

If the liquidity constraint in the second period is not binding, $\kappa \geq 0$, the firm does not take an options position at $t=1$ at all, $Z_{1}^{*}=0$, and adjusts the futures position for the second period to a full hedge, $X_{1}^{*}=Q^{*}-X_{0}^{*}$.

The first part of Proposition 2 proves that the existence of liquidity risk establishes a hedging role for options on futures. If the liquidity constraint at $t=1$ is binding, $\kappa<0$, the firm optimally sells options on futures and under-hedges with futures contracts. This implies that a risk-free position (as given by $Z_{1}=0$ and $\left.X_{1}=Q-X_{0}\right)$ is not optimal given $\kappa<0$. The rationale behind this result is based on a cost argument and a risk argument.

Consider the cost argument first. As $\kappa<0$, the firm has to borrow the amount $|\kappa|$ which is costly. A short position in options on futures generates a cash inflow of $\left|P_{1} Z_{1}\right|$. This cash inflow reduces the amount that is ultimately borrowed from $t=1$ until $t=2$ and therefore reduces the borrowing costs associated with the loss generated by the derivatives portfolio during the first period. ${ }^{14}$

\footnotetext{
${ }^{14}$ Selling options on futures, combined with a long position in futures contracts, is (almost) identical to borrowing at the risk-free rate. See Hull (2006, Ch. 14). Therefore, assuming that the firm can trade options at a price of $P_{1}$ allows the firm to indirectly borrow at the risk-free rate. This is not inconsistent with the assumption that the firm, if borrowing directly, has to pay a markup for two reasons: Ordinary lenders often times are less well-informed about a borrowers derivatives portfolio compared to exchanges that closely monitor each market participants position. This is in line with the fact that exchanges are able to classify market participants into hedgers
} 
Next, consider the risk argument. Selling call options on futures creates an additional exposure to $\tilde{S}$ : If $S$ exceeds the strike price $f_{1}$, the options will be exercised against the firm such that there is a cash outflow at $t=2$. In other words, $W^{*}$ is no longer linear but only piecewise linear with a kink at $S=f_{1}$. The slope of the first linear part depends on the futures position only, the slope of the second depends on the options position as well. As Proposition 2 claims, the optimal futures position is an underhedge. Consequently, $\partial W^{*} / \partial S>0$ for $S \in\left[\underline{S}, f_{1}\right]$. The size of the options position is such that $\partial W^{*} / \partial S<0$ for $S \in\left(f_{1}, \bar{S}\right]$. In other words, $W^{*}$ is inversely Vshaped in $S$. This minimizes risk as measured by the variability of marginal utility, given that $\partial W^{*} / \partial S$ is kinked.

In sum, given the need to raise costly external funds, $\kappa<0$, the firm is willing to take some $\tilde{S}$-risk in order to benefit from a reduction in the amount to be borrowed.

The second part of Proposition 2 shows that options on futures are redundant for hedging purposes if and only if the firm does not realize any losses on its hedging position by the end of the first period. In this case, the firm fully hedges over the second period using futures contracts only. ${ }^{15}$ Its total cash flow at $t=2$ simplifies to $f_{1}\left(Q-X_{0}\right)-C(Q)+I+Z_{0} \max \left[f_{1}-f_{0}, 0\right]-P_{0} Z_{0}+f_{0} X_{0}$ which is deterministic.

and non-hedgers; hedgers have to provide (significantly) lower initial margins. The second reason for why the firm can (effectively) trade at $P_{1}$ is that the exchange can use the futures position as a collateral for the firm's options position, guaranteeing that the firm will be able to deliver if the options are exercised.

${ }^{15}$ This is in line with the result derived by Wong and $\mathrm{Xu}$ (2006) for another type of liquidity constraint. 


\section{$5 \quad$ Numerical results}

The numerical results are based on the following assumptions: The futures price follows a multiplicative random walk with $\tilde{f}_{t}=\tilde{\theta}_{t} f_{t-1}$ where $\mathrm{E}_{t-1}\left[\tilde{\theta}_{t}\right]=1$ and the $\tilde{\theta}_{t}$ are i.i.d., $t=1,2$. In particular, we assume that $\tilde{\theta}_{t}$ follows a three-point distribution where $\theta_{t}$ is either $u, 1$ or $d, u>1>d>0 .{ }^{16}$ We also assume that $f_{0}=1, u=1.25$, $d=0.8, \operatorname{prob}(u)=4 / 15$ and $\operatorname{prob}(d)=1 / 3$ such that $\mathrm{E}_{0}\left[\tilde{f}_{1}\right]=\mathrm{E}_{0}[\tilde{S}]=1$ and the one-period volatility of the futures return is $\sigma^{2}=0.03$. The decision maker is assumed to have a power utility function with constant relative risk aversion of $\alpha$.

Subsections 5.1 and 5.2 focus on the optimal futures and options positions and their comparative statics with respect to risk aversion and price volatility assuming that the firm's output is exogenously given.

Other simulations clearly indicate a negative relation between the markup rate $\tau$ and optimal output $Q^{*}$. This illustrates the well-known result that introducing an additional risk (here in the form of liquidity risk) decreases production if the additional risk cannot be perfectly hedged. ${ }^{17}$ In order to save space, these simulations are not presented here.

\subsection{Optimal hedging decisions}

The firm's output is exogenously fixed at $Q=100$ such that all futures positions can be easily interpreted as percentage hedge ratios. The deterministic payment $I$ is set equal to total production costs, $C(Q)=I$. Relative risk aversion is 2. Table I presents the optimal values for $X_{0}, X_{1}, Z_{0}$ and $Z_{1}$ for different levels of the markup

\footnotetext{
${ }^{16}$ The assumption of a multiplicative random walk has no significance for the results. We use a multiplicative random walk as this implies a constant volatility of the futures return. Chang and Wong (2003) and Lien and $\mathrm{Li}$ (2003) use an additive random walk over several periods. In a two-period framework similar to ours, Wong (2004a, 2004b) and Wong and Xu (2006) assume an additive relation over the second period .

${ }^{17}$ See, for example, Broll et al. (1995) and Viaene and Zilcha (1998).
} 
rate $\tau{ }^{18}$ The benchmark case of $\tau=0$ (Proposition 1 ) is given in the first row.

\begin{tabular}{|c|c|c|c|c|c|c|c|}
\hline \multirow{3}{*}{$\begin{array}{l}\text { markup } \\
\text { rate per } \\
\text { period } \tau\end{array}$} & \multirow{2}{*}{\multicolumn{2}{|c|}{$\begin{array}{c}\text { decision } \\
\text { taken at } t=0\end{array}$}} & \multicolumn{5}{|c|}{ decision taken at $t=1$} \\
\hline & & & \multicolumn{3}{|c|}{ given $f_{1}>f_{0}$} & \multicolumn{2}{|c|}{ given $f_{1} \leq f_{0}$} \\
\hline & $X_{0}^{*}$ & $Z_{0}^{*}$ & $\kappa$ & $X_{1}^{*}$ & $Z_{1}^{*}$ & $X_{1}^{*}$ & $Z_{1}^{*}$ \\
\hline 0.00 & 100.0 & 0.0 & -25.0 & 0.0 & 0.0 & 0.0 & 0.0 \\
\hline 0.01 & 98.4 & 0.0 & -24.6 & -3.4 & -9.0 & 1.6 & 0.0 \\
\hline 0.02 & 96.7 & 0.0 & -24.2 & -6.8 & -18.2 & 3.3 & 0.0 \\
\hline 0.03 & 95.2 & 0.0 & -23.8 & -10.5 & -27.5 & 4.8 & 0.0 \\
\hline 0.04 & 93.6 & 0.0 & -23.4 & -14.1 & -36.9 & 6.4 & 0.0 \\
\hline 0.05 & 92.1 & 0.0 & -23.0 & -17.9 & -46.4 & 7.9 & 0.0 \\
\hline 0.06 & 90.7 & 0.0 & -22.7 & -21.8 & -56.0 & 9.3 & 0.0 \\
\hline 0.07 & 89.3 & 0.0 & -22.3 & -25.8 & -65.8 & 10.7 & 0.0 \\
\hline 0.08 & 87.7 & 0.0 & -21.9 & -29.9 & -75.8 & 12.3 & 0.0 \\
\hline 0.09 & 86.5 & 0.0 & -21.6 & -34.2 & -85.9 & 13.5 & 0.0 \\
\hline 0.10 & 85.2 & 0.0 & -21.3 & -38.6 & -96.1 & 14.8 & 0.0 \\
\hline
\end{tabular}

Table I: Optimal hedging positions for different levels of markup rate

The first column shows by how much the borrowing rate exceeds the risk-free rate. The next two columns present the optimal hedging decisions made at $t=0$. The remaining columns show the optimal decisions taken at $t=1$, conditional on whether the liquidity constraint is binding (in which case $f_{1}>f_{0}$ and $\kappa<0$ ) or not.

Consider the decisions taken at $t=1$ first. For $f_{1}>f_{0}$, the optimal derivatives position taken at $t=0$ generates a cash outflow such that $\kappa<0$ (column 4 ); the liquidity constraint is binding. Columns 5 and 6 show that the firm sells options on futures, $Z_{1}^{*}<0$, and reduces its futures position, $X_{1}^{*}<0$. For $f_{1} \leq f_{0}$, the optimal derivatives position taken at $t=0$ generates a non-negative cash flow at $t=1$, $\kappa \geq 0 .{ }^{19}$ The last two columns illustrate Proposition 2 as $X_{0}^{*}+X_{1}^{*}=Q=100$ and

\footnotetext{
${ }^{18}$ The credit spread for firms with investment grade ratings was well below $2 \%$ in the US (King and Khang, 2005; Yua, 2005; Campbell and Taksler, 2003; Duffee, 1998). However for firms with lower credit ratings, spreads were considerably higher. Using a sample of bonds issued by corporations from 15 different countries, Gabbi and Sironi (2002) indicates that bonds with a Standard \& Poor's rating of B have an average spread of $5.95 \%$, where bonds with CCC rating have an average spread of $9.05 \%$. More recently, credit spreads have widened significantly in the wake of the subprime crisis.

${ }^{19}$ The values for $\kappa$ given that $f_{1} \leq f_{0}$ are not shown in Table I.
} 
$Z_{1}^{*}=0$

To be more specific, focus on the case where $\tau=5 \%$. At $t=1$, the cash flow of the firm depends on the realization of $f_{1}$ and any options position taken at this date. Given $X_{0}^{*}=92.1$ and $Z_{0}^{*}=0$, we have $\kappa=18.4$ if $f_{1}<f_{0}$ and $\kappa=0$ if $f_{1}=f_{0}$. In both cases, no liquidity need arises at $t=1$ and the firm adjusts the futures position to a full hedge (Proposition 2). However, when $f_{1}>f_{0}$, a liquidity need arises as $\kappa=X_{0}^{*}\left(f_{0}-f_{1}\right)=-23.0$. In order to generate cash, the firm sells options, $Z_{1}^{*}=-46.4$, and reduces the amount to be borrowed by the amount of the options premium, $-P_{1} Z_{1}^{*}=3.9$. This options position generates an additional exposure to $\tilde{S}$. To manage this risk, the firm adjusts the position in futures downwards, $X_{1}^{*}=-17.9$.

Next, consider the decisions taken at $t=0$. Table I shows that the firm optimally under-hedges with futures contracts at $t=0$ if $\tau>0$. The optimal futures position, $X_{0}^{*}$, decreases in the markup rate. For example, a firm facing a markup of $5 \%$ above the risk-free rate only hedges $92.1 \%$ of its output at $t=0$ with futures contracts.

The economic intuition behind this result is the following: On the one hand, risk aversion creates an incentive to reduce the exposure to price risk. At $X_{0}=Q$, this price risk is completely hedged. On the other hand, any futures position taken at $t=0$ exposes the firm to liquidity risk: If the futures price $f_{1}$ is such that the futures position generates a cash outflow at $t=1$, the firm will have to borrow. Borrowing is more costly the higher $\tau$. Given $f_{1}>f_{0}$, the firm has to borrow more the higher the position in futures taken at $t=0$. As Table I shows, the optimal futures position is a compromise between managing price risk and reducing the exposure to liquidity risk: As $\tau$ increases, liquidity risk becomes more pronounced such that the firm reduces its exposure to this risk by choosing a smaller optimal futures position.

Column 3 indicates that the firm does not take any position in options on futures 
at $t=0$. This might seem surprising as the liquidity risk materializes in exactly those states in which options generate a cash inflow. Consequently, one would have expected the firm to buy call options already at $t=0$ as a means to generate additional cash at $t=1$ in those states, i.e. to hedge against the liquidity risk using options. As $\tau$ increases, the borrowing costs incurred from $t=1$ to $t=2$ grow such that the incentive to buy options at $t=0$ in order to create a cash inflow at $t=1$ increases as well. However, the firm is not only liquidity constrained at $t=1$ but also liquidity constrained at $t=0$. Any long options position taken at $t=0$ will have to be financed through borrowing at $\tau$ until at least $t=1$. This can be interpreted as the cost of buying options at $t=0$. Both the benefit and the cost increase in $\tau$. Our result indicates that the benefits are exactly outweighed by the cost such that the net effect of an increase in $\tau$ on $Z_{0}^{*}$ is zero. Consequently, no options position is taken at $t=0$.

This finding is not in line with Wong and $\mathrm{Xu}$ (2006) who show that, given their type of liquidity constraint, the firm should buy call options at $t=0$. However, their model is based on the assumption that there is a liquidity constraint at $t=1$ but no such constraint at $t=0$. In other words, there are no (additional) costs of buying fairly priced options at $t=0$ in their model but only benefits. Hence, it is not surprising that options will be used at $t=0$ in their framework but not in the model discussed here. 


\subsection{Comparative statics}

This subsection focuses on the effects of changes in volatility and risk aversion. Consider an increase in the volatility of the futures price: As proven in Proposition 1, in the absence of liquidity risk the firm optimally fully hedges with futures contracts irrespective of the distribution of the spot price $\tilde{S}$; options are not used. However, when the firm is liquidity constrained, price volatility matters: Given that there is a cash outflow at $t=1$, its expected value increases in volatility. Taken in isolation, this makes futures hedging over the first period less attractive. At the same time, higher volatility implies higher potential hedging benefits over both periods, making futures hedging more attractive. Hence, the impact of price volatility on the optimal futures position is not clear a priori.

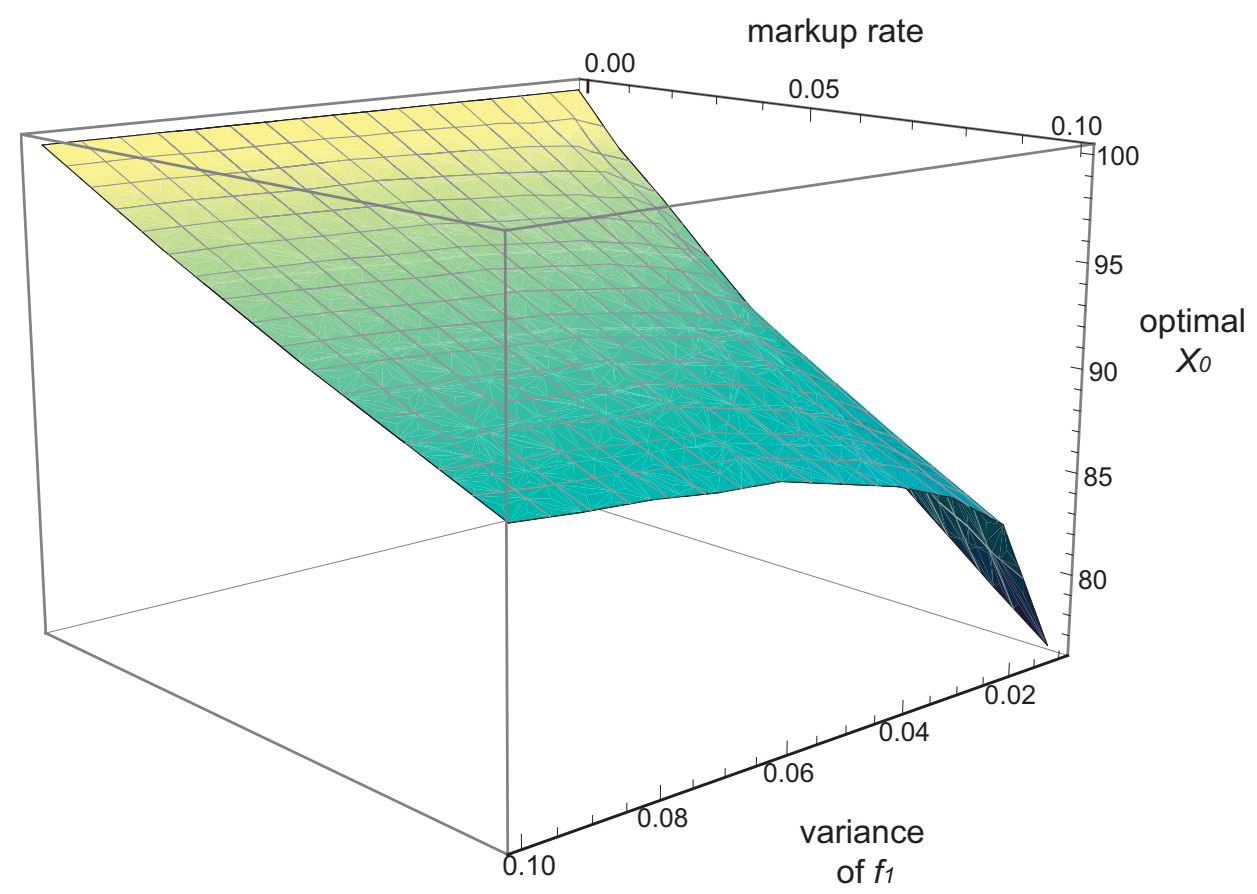

Figure 1: The effect of price volatility on $X_{0}^{*}$ 
Figure 1 shows the optimal futures position taken at $t=0, X_{0}^{*}$, for various combinations of the markup rate $\tau$ and the volatility of the futures price $\tilde{f}_{1} \cdot{ }^{20}$ Figure 1 indicates that the optimal futures position taken at $t=0$ increases in volatility over the whole range of markup rates. It also shows that this increase is more pronounced for higher values of $\tau .^{21}$ Therefore, Figure 1 indicates that the more pronounced hedging benefit outweighs the larger liquidity risk, given an increase in volatility.

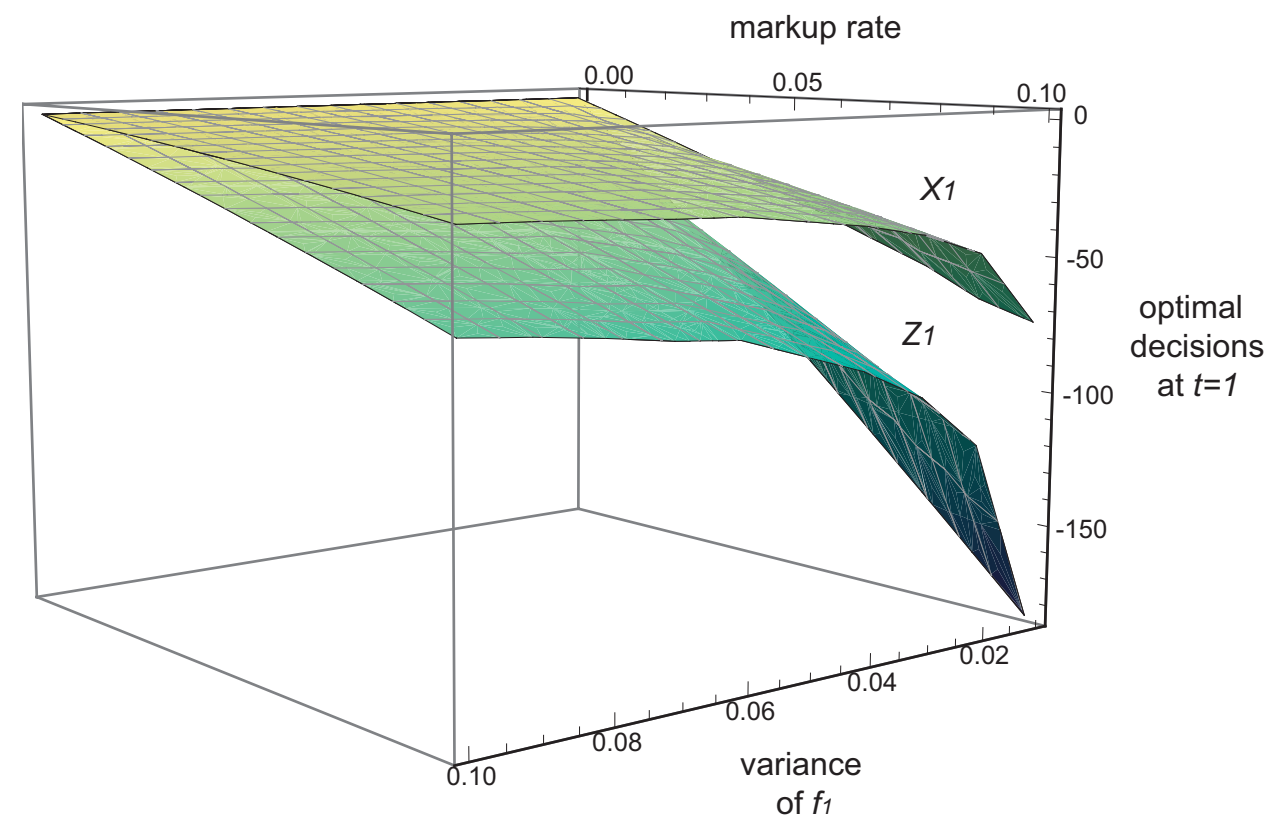

Figure 2: The effect of price volatility on $X_{1}^{*}$ and $Z_{1}^{*}$ for $\kappa<0$

Figure 2 illustrates the impact of price volatility on the hedging decisions taken at $t=1, X_{1}^{*}$ and $Z_{1}^{*}$, given that the liquidity constraint is binding, $\kappa<0$. It indicates that the firm sells less options on futures as volatility increases. It also indicates that the downward adjustment of the futures position decreases in volatility as well.

\footnotetext{
${ }^{20}$ Changes in volatility are modeled as changes in $u$ and $d=1 / u$, accompanied by an appropriate adjustment in $\operatorname{prob}(d)$ in order to ensure that $f_{t}=\mathrm{E}_{t}\left[\tilde{f}_{t+1}\right] . \operatorname{prob}(u)$ remains constant at $4 / 15$. Relative risk aversion equals 2. The optimal options position remains unchanged at $Z_{0}^{*}=0$.

${ }^{21}$ These results are in line with those derived by Korn (2004) for a different set of assumptions including the absence of options on futures. The fact that they are not in line with Deep's (2002) result is caused by the difference in the modeling of the liquidity constraint.
} 
Again, these effects are more pronounced for larger values of $\tau$.

The impact of changes in risk aversion is briefly illustrated in Table II, assuming a markup rate of $5 \% .{ }^{22}$

\begin{tabular}{|c|c|c|c|c|c|c|c|}
\hline \multirow{3}{*}{$\begin{array}{c}\text { relative } \\
\text { risk } \\
\text { aversion } \alpha\end{array}$} & \multirow{2}{*}{\multicolumn{2}{|c|}{$\begin{array}{c}\text { decision } \\
\text { taken at } t=0\end{array}$}} & \multicolumn{5}{|c|}{ decision taken at $t=1$} \\
\hline & & & \multicolumn{3}{|c|}{ given $f_{1}>f_{0}$} & \multicolumn{2}{|c|}{ given $f_{1} \leq f_{0}$} \\
\hline & $X_{0}^{*}$ & $Z_{0}^{*}$ & $\kappa$ & $X_{1}^{*}$ & $Z_{1}^{*}$ & $X_{1}^{*}$ & $Z_{1}^{*}$ \\
\hline 1.00 & 86.8 & 0.0 & $\begin{array}{l}-21.7 \\
\end{array}$ & -39.4 & -94.7 & 13.2 & 0.0 \\
\hline 1.50 & 90.4 & 0.0 & -22.6 & -25.0 & -62.2 & 9.6 & 0.0 \\
\hline 2.00 & 92.1 & 0.0 & -23.0 & -17.9 & -46.4 & 7.9 & 0.0 \\
\hline 2.50 & 93.2 & 0.0 & -23.3 & -13.7 & -36.9 & 6.8 & 0.0 \\
\hline 3.00 & 93.9 & 0.0 & -23.5 & -11.0 & -30.7 & 6.1 & 0.0 \\
\hline 3.50 & 94.4 & 0.0 & -23.6 & -9.0 & -26.3 & 5.6 & 0.0 \\
\hline 4.00 & 94.7 & 0.0 & -23.7 & -7.4 & -22.9 & 5.3 & 0.0 \\
\hline
\end{tabular}

Table II: Optimal hedging position for different degrees of relative risk aversion

The first column indicates the degree of relative risk aversion. (Otherwise, Table II has the same structure as Table I.) It shows that the optimal futures position taken at $t=0$ increases moderately in risk aversion. This reflects the fact that the hedging benefits are valued more highly when the decision maker exhibits higher risk aversion. If the liquidity constraint is binding at $t=1$, the firm reduces its short position in options on futures as risk aversion increases. It also reduces the number of futures contracts sold. Hence, a firm with higher risk aversion is willing to accept higher borrowing costs in order to reduce the additional exposure to price risk created by selling options. Table II indicates that the effect of an increase in risk aversion on $X_{1}^{*}$ and, in particular, on $Z_{1}^{*}$ can be significant.

\footnotetext{
${ }^{22}$ Gollier (2001, Ch. 2) argues for levels of relative risk aversion between unity and four.
} 


\section{Conclusions}

This paper analyzes the impact of liquidity risk on the optimal production and risk management decisions of a risk-averse firm that can manage price risk with futures contracts and options on these futures. Liquidity risk created by marking to market as well as the use of options might create cash flows prior to the hedging horizon.

Our results show that liquidity risk lowers the optimal futures hedge ratio in the first period. It also reduces production. The optimal futures position is a compromise between two conflicting objectives: The first is to reduce the exposure to price risk, the second is to avoid the cost created by liquidity risk. No options position is taken in the first period. If liquidity risk materializes prior to the hedging horizon, the firm optimally sells options at the beginning of the second period and adjusts its futures position in order to cope with the additional exposure created by the options position. If liquidity risk does not materialize, the problem in the second period is isomorphic to the standard hedging model such that the firm adjusts the futures position to a full hedge.

The comparative statics results are straightforward: The optimal hedge ratio in the first period decreases in the markup rate and increases in risk aversion and price volatility. The optimal options position in the second period changes inversely.

In contrast to the results obtained by Wong and $\mathrm{Xu}$ (2006), our paper shows that there is no hedging role for options in the first period but in the second. This difference arises because Wong and Xu (2006) assume a different type of liquidity constraint in which the entire derivatives position has to be liquidated if the interim cash outflow created by marking to market exceeds a certain threshold. In such a framework, there can only be a hedging role for options in the first period. In the present paper, options can also be used in the second period which, as the numerical 
results show, is optimal to do if liquidity risk materializes. Hence, the present paper also shows how sensitive the optimal use of options depends on the setup of the model. 


\section{References}

Battermann, H.L., Braulke, M., Broll, U., \& Schimmelpfenning, J. (2000). The preferred hedge instrument. Economics Letters, 66, 85-91.

Benninga, S., \& Oosterhof, C. (2004). Hedging with forwards and puts in complete and incomplete markets. Journal of Banking and Finance, 28, 1-17.

Broll, U., Wahl, J.E., \& Zilcha, I. (1995). Indirect hedging and exchange rate risk. Journal of International Money and Finance, 14, 667-678.

Campbell, J.Y., \& Taksler, G.B. (2003). Equity volatility and corporate bond yields. Journal of Finance, 58, 2321-2349.

Chang, E.C., \& Wong, K.P. (2003). Cross-hedging with currency options and futures. Journal of Financial and Quantitative Analysis, 38, 555-574.

Committee on Payment and Settlement Systems. (1998). OTC derivatives: Settlement procedures and counterparty risk management. Basle, Switzerland: Bank for International Settlements.

Culp, C.L., \& Miller, M.H. (1995). Metallgesellschaft and the economics of synthetic storage. Journal of Applied Corporate Finance, 7, 62-76.

Deep, A. (2002). Optimal dynamic hedging using futures under a borrowing constraint. Working paper, Bank for International Settlements, Basle, Switzerland.

Duffee, G.R. (1998). The relation between treasury yields and corporate bond yield spreads. Journal of Finance, 60, 1673-1712.

Gabbi, G., \& Sironi, A. (2002). Which factors affect corporate bond pricing? Empirical evidence from eurobonds primary market spreads. Working Paper, Bocconi University, Milan, Italy.

Gollier, C. (2001). The economics of risk and time. Cambridge: MIT Press.

Holthausen, D.M. (1979). Hedging and the competitive firm under price uncertainty. American Economic Review, 69, 989-995.

Hull, J.C. (2006). Options, futures and other derivatives (6th ed.). Upper Saddle River: Prentice-Hall.

Kimball, M.S. (1990). Precautionary saving in the small and in the large. Econometrica, $58,53-73$.

Kimball, M.S. (1993). Standard risk aversion. Econometrica, 61, 589-611.

King, T.H.D., \& Khang, K. (2005). On the importance of systematic risk factors in explaining the cross-section of corporate bond yield spreads. Journal of Banking and Finance, 29, 3141-3158.

Korn, O. (2004). Liquidity risk and hedging decisions. Zeitschrift für Betriebswirtschaft, $74,837-857$ 
Lapan, H., Moschini, G., \& Hanson, S.D. (1991). Production, hedging and speculative decisions with options and futures markets. American Journal of Agricultural Economics, 73, 66-74.

Lien, D. (2003). The effect of liquidity constraints on futures hedging. Journal of Futures Markets, 23, 603-613.

Lien, D., \& Li, A. (2003). Futures hedging under mark-to-market risk. Journal of Futures Markets, 23, 389-398.

Lien, D., \& Wong, K.P. (2002). Delivery risk and the hedging role of options. Journal of Futures Markets, 22, 339-354.

Mello, A.S. \& Parsons, J.E. (1995). Maturity structure of a hedge matters: Lessons from the Metallgesellschaft debacle. Journal of Applied Corporate Finance, 8, 106-120.

Viaene, J.M., \& Zilcha, I. (1998). The behavior of competitive exporting firms under multiple uncertainty. International Economic Review, 39, 591-609.

Wong, K.P. (2004a). Hedging, liquidity and the competitive firm under price uncertainty. Journal of Futures Markets, 24, 697-706.

Wong, K.P. (2004b). Liquidity constraints and the hedging role of futures spreads. Journal of Futures Markets, 24, 909-921.

Wong, K.P., \& Xu, J. (2006). Liquidity risk and the hedging role of options. Journal of Futures Markets, 26, 789-808.

Yua, F. (2005). Accounting transparency and the term structure of credit spreads. Journal of Financial Economics, 75, 53-84.

Zhoo, Z. (1998). An equilibrium analysis of hedging with liquidity constraints, speculation and government price subsidy in a commodity market. Journal of Finance, 53, 17051736 . 


\section{Appendix}

\section{Proof of Proposition 1}

The optimization problem has to be solved recursively. At $t=1$, the firm decides upon $X_{1}^{b}$ and $Z_{1}^{b}$, given $f_{1}, P_{1}, Q^{b *}, X_{0}^{b *}$ and $Z_{0}^{b *}$. As the derivatives markets are jointly unbiased, the first-order conditions for $X_{1}^{b *}$ and $Z_{1}^{b *}$ can be written as

$$
\begin{aligned}
& \mathrm{E}_{1}\left[U^{\prime}\left(\tilde{W}^{b *}\right)\left(f_{1}-\tilde{S}\right)\right]=-\operatorname{cov}_{1}\left(U^{\prime}\left(\tilde{W}^{b *}\right), \tilde{S}\right)=0 \quad \forall f_{1}, \\
& \mathrm{E}_{1}\left[U^{\prime}\left(\tilde{W}^{b *}\right)\left(\max \left[\tilde{S}-f_{1}, 0\right]-P_{1}\right)\right] \\
& \quad=\operatorname{cov}_{1}\left(U^{\prime}\left(\tilde{W}^{b *}\right), \max \left[\tilde{S}-f_{1}, 0\right]\right)=0 \quad \forall f_{1} .
\end{aligned}
$$

Due to the concavity of the problem, the solution is unique. Substituting the $X_{1}^{b}=Q^{b}-X_{0}^{b}$ and $Z_{1}^{b}=0$ as a candidate solution into the firm's cash flow definition yields

$$
\begin{aligned}
\tilde{W}^{b}= & \tilde{S} Q^{b}-C\left(Q^{b}\right)+I+\left(X_{0}^{b}+Q^{b}-X_{0}^{b}\right)\left(f_{1}-\tilde{S}\right)+X_{0}^{b}\left(f_{0}-f_{1}\right) \\
& -P_{0} Z_{0}^{b}+Z_{0}^{b} \max \left[f_{1}-f_{0}, 0\right] \\
= & f_{1} Q^{b}-C\left(Q^{b}\right)+I+X_{0}^{b}\left(f_{0}-f_{1}\right)+Z_{0}^{b} \max \left[f_{1}-f_{0}, 0\right]-P_{0} Z_{0}^{b} \quad \forall f_{1} .
\end{aligned}
$$

As this is a deterministic amount, conditions (7) and (8) are satisfied. Hence, the firm's optimal derivatives position at $t=1$ is given by $X_{1}^{b *}=Q^{b}-X_{0}^{b}$ and $Z_{1}^{b *}=0$.

The first period problem is given by $\max _{Q^{b}, X_{0}^{b}, Z_{0}^{b}} \mathrm{E}_{0}\left[U\left(\tilde{W}^{b}\left(X_{1}^{b *}, Z_{1}^{b *}\right)\right)\right]$. Again using the unbiasedness of the derivatives markets, the first-order conditions for $X_{0}^{b *}$ and $Z_{0}^{b *}$ reduce to

$$
\begin{gathered}
-\operatorname{cov}_{0}\left(\tilde{f}_{1}, U^{\prime}\left(\tilde{W}^{b *}\right)\right)=0, \\
\operatorname{cov}_{0}\left(\max \left[\tilde{f}_{1}-f_{0}, 0\right], U^{\prime}\left(\tilde{W}^{b *}\right)\right)=0 .
\end{gathered}
$$

Substituting (10) into the first-order condition for $Q^{b *}$, given by

$$
\mathrm{E}_{0}\left[\tilde{f}_{1}-C^{\prime}\left(Q^{b *}\right)\right] \mathrm{E}_{0}\left[U^{\prime}\left(\tilde{W}^{b *}\right)\right]+\operatorname{cov}_{0}\left(\tilde{f}_{1}, U^{\prime}\left(\tilde{W}^{b *}\right)\right)=0
$$


and dividing by $\mathrm{E}_{0}\left[U^{\prime}\left(\tilde{W}^{b, *}\right)\right]>0$ directly leads to $\mathrm{E}_{0}\left[\tilde{f}_{1}\right]=f_{0}=C^{\prime}\left(Q^{b, *}\right)$. If $C^{\prime-1}(\cdot)$ denotes the inverse of the firm's marginal cost function, we have $Q^{b, *}=C^{\prime-1}\left(f_{0}\right)$.

Consider the vector $\left(X_{0}^{b}, Z_{0}^{b}, Q^{b *}\right)=\left(Q^{b *}, 0, C^{\prime-1}\left(f_{0}\right)\right)$ as a candidate solution. Using the same logic as above, it is straightforward to show that the firm's profits at $t=0$ are deterministic such that conditions (10) and (11) are satisfied. As the first period problem is concave as well, its unique solution is given by $X_{0}^{b *}=Q^{b *}=$ $C^{\prime-1}\left(f_{0}\right)$ and $Z_{0}^{b *}=0$. As the optimal production decision is neither affected by the firm's degree of risk aversion nor by its assessment of the joint distribution of $\tilde{f}_{1}$ and $\tilde{S}$, separation holds.

\section{Proof of Proposition 2}

The proof is based on ruling out combinations of positions in futures and options on futures as being incompatible with the first-order conditions. The proof proceeds as follows: In part (a), we use the first-order condition for $X_{1}^{*}$ in (13) to rule out all possible combinations except three. In part (b), we deal with these three cases by using the first-order condition for $Z_{1}^{*}$ in addition. Part (b) also briefly analyzes the case of $\kappa \geq 0$. Parts (c) and (d) deal with the case of $\kappa<0$. Between these parts, we will present and prove a lemma that will be used in part (d).

(a) Given $f_{1}, P_{1}, Q^{*}, X_{0}^{*}$ and $Z_{0}^{*}$, the firm solves the problem in (6). Due to the concavity of this problem, its solution is unique. As the derivatives markets are jointly unbiased, the first-order condition for $X_{1}^{*}$ is given by

$$
\mathrm{E}_{1}\left[U^{\prime}\left(\tilde{W}^{*}\right)\left(f_{1}-\tilde{S}\right)\right]=-\operatorname{cov}_{1}\left(U^{\prime}\left(\tilde{W}^{*}\right), \tilde{S}\right)=0 \quad \forall f_{1}
$$

Condition (13) holds if and only if either $W^{*}$ is a constant for all $S$ or there is at least one interval of $S$ in which $W^{*}$ increases in $S, \partial W^{*} / \partial S>0$, and at least one other interval of $S$ in which it decreases in $S, \partial W^{*} / \partial S<0$ as $U^{\prime \prime}(\cdot)<0$. The 
definition of $W$ in (3) implies

$$
\frac{\partial W}{\partial S}= \begin{cases}Q-X_{0}-X_{1}+Z_{1} & \text { for } S>f_{1} \\ Q-X_{0}-X_{1} & \text { for } S \leq f_{1}\end{cases}
$$

(14) shows that the sign of $\partial W^{*} / \partial S$ is the same within each of the intervals $\left[\underline{S}, f_{1}\right]$ and $\left(f_{1}, \bar{S}\right]$. Hence, if the sign of $\partial W^{*} / \partial S$ is to change in $S$, it has to be positive in one of these intervals and negative in the other.

Next, we use condition (13) to show by contradiction that certain combinations of positions in futures and options on futures cannot be optimal. Firstly, suppose that $X_{1}^{*}>Q^{*}-X_{0}^{*}$ and $Z_{1}^{*} \leq 0$. This implies $\partial W^{*} / \partial S<0$ for all $S$. It therefore contradicts (13). Secondly, suppose that $X_{1}^{*}<Q^{*}-X_{0}^{*}$ and $Z_{1}^{*} \geq 0$. It follows directly from (14) that $\partial W^{*} / \partial S>0$ for all $S$. Again, this raises a contradiction to (13). Thirdly, suppose that $X_{1}^{*}=Q^{*}-X_{0}^{*}$ and that $Z_{1}^{*}>[<] 0$. (14) implies that $\partial W^{*} / \partial S=0$ for $S \in\left[\underline{S}, f_{1}\right]$ and positive [negative] otherwise. Hence, condition (13) is violated.

(b) It has been shown so far that the only combinations that do not contradict (13) are those where $X_{1}>[=][<] Q-X_{0}$ and $Z_{1}>[=][<] 0$ at the same time. These cases will be analyzed next, using the first-order condition for $Z_{1}^{*}$ as well. The exact form of this condition depends on the value of $\min \left[\kappa-P_{1} Z_{1}, 0\right]$ at the optimum. If $\min \left[\kappa-P_{1} Z_{1}^{*}, 0\right]=0$, the first-order condition is given by

$$
\begin{aligned}
& \mathrm{E}_{1}\left[U^{\prime}\left(\tilde{W}^{*}\right)\left(\max \left[\tilde{S}-f_{1}, 0\right]-P_{1}\right)\right] \\
& =\operatorname{cov}_{1}\left(U^{\prime}\left(\tilde{W}^{*}\right), \max \left[\tilde{S}-f_{1}, 0\right]\right)=0,
\end{aligned}
$$

using the unbiasedness of the derivatives markets. Unbiasedness also implies that the first-order condition for $Z_{1}^{*}$, given $\min \left[\kappa-P_{1} Z_{1}^{*}, 0\right]=\kappa-P_{1} Z_{1}^{*}$, is

$$
\begin{aligned}
& \mathrm{E}_{1}\left[U^{\prime}\left(\tilde{W}^{*}\right)\left(\max \left[\tilde{S}-f_{1}, 0\right]-(1+\tau) P_{1}\right)\right] \\
& =\operatorname{cov}_{1}\left(U^{\prime}\left(\tilde{W}^{*}\right), \max \left[\tilde{S}-f_{1}, 0\right]\right)-\tau P_{1} \mathrm{E}_{1}\left[U^{\prime}\left(\tilde{W}^{*}\right)\right]=0 .
\end{aligned}
$$


Let us look at cases now. Assume that $\kappa \geq 0$ and suppose that $X_{1}^{*}=Q^{*}-X_{0}^{*}$ and $Z_{1}^{*}=0$. It follows that condition (15) applies. As $\partial W^{*} / \partial S=0$ for all $S$ in this case, $W^{*}$ is a constant such that conditions (13) and (15) are both met and the vector $\left(X_{1}^{*}, Z_{1}^{*}\right)=\left(Q^{*}-X_{0}^{*}, 0\right)$ characterizes the unique optimum, given $\kappa \geq 0$.

(c) It remains to find the optimal positions for $\kappa<0$. Suppose $\left(X_{1}^{*}, Z_{1}^{*}\right)=$ $\left(Q^{*}-X_{0}^{*}, 0\right)$. In this case, condition (16) applies. $W^{*}$ is a constant such that the covariances in (13) and (16) are zero, but the second summand in (16) is positive since $\tau, P_{1}, U^{\prime}(\cdot)>0$. Hence, condition (16) is violated such that this vector cannot be optimal for $\kappa<0$.

The remainder of the proof rules out that $X_{1}>Q^{*}-X_{0}^{*}$ and $Z_{1}>0$ is optimal such that the $X_{1}^{*}<Q^{*}-X_{0}^{*}$ and $Z_{1}^{*}<0$ is the optimal decision for $\kappa<0$. Before proceeding, we state and prove a lemma that will be used later in part (d).

Lemma 1 If $\partial W^{*} / \partial S<0$ for $S \in\left[\underline{S}, f_{1}\right]$ and $\partial W^{*} / \partial S>0$ for $S \in\left(f_{1}, \bar{S}\right]^{23}$, there exist two distinct points, $S_{1} \in\left(\underline{S}, f_{1}\right)$ and $S_{2} \in\left(f_{1}, \bar{S}\right)$, such that $U^{\prime}\left(W^{*}(S)\right) \geq$ $\mathrm{E}_{1}\left[U^{\prime}\left(W^{*}(\tilde{S})\right)\right]$ for all $S \in\left[S_{1}, S_{2}\right]$ and $U^{\prime}\left(W^{*}(S)\right)<\mathrm{E}_{1}\left[U^{\prime}\left(W^{*}(\tilde{S})\right)\right]$ for all $S \in$ $\left[\underline{S}, S_{1}\right) \cup\left(S_{2}, \bar{S}\right]$, where the equality holds at $S=S_{1}$ and $S=S_{2}$ only.

Proof of Lemma 1: $U^{\prime \prime}(\cdot)<0$ implies that $U^{\prime}\left(W^{*}(S)\right)$ is strictly increasing for all $S \in\left[\underline{S}, f_{1}\right]$ and strictly decreasing for all $S \in\left(f_{1}, \bar{S}\right]$. In other words, $U^{\prime}\left(W^{*}(S)\right)$ attains a unique maximum at $f_{1}$. Since $\mathrm{E}_{1}\left[U^{\prime}\left(W^{*}(\tilde{S})\right)\right]$ is the expected value of $U^{\prime}\left(W^{*}(S)\right)$, there must exist at least one and at most two distinct points in $(\underline{S}, \bar{S})$ at which $U^{\prime}\left(W^{*}(S)\right)=\mathrm{E}_{1}\left[U^{\prime}\left(W^{*}(\tilde{S})\right)\right]$. In the following, it will be shown that a contradiction arises if there is only one such point.

Suppose first that $U^{\prime}\left(W^{*}(\underline{S})\right) \geq \mathrm{E}\left[U^{\prime}\left(W^{*}(\tilde{S})\right)\right]$. Hence, a unique point $\hat{S} \in$ $\left(f_{1}, \bar{S}\right)$ has to exist such that $U^{\prime}\left(W^{*}(S)\right)>\mathrm{E}_{1}\left[U^{\prime}\left(W^{*}(\tilde{S})\right)\right]$ for all $S \in(\underline{S}, \hat{S})$ and

\footnotetext{
${ }^{23}$ Using (13) and (14), this condition directly implies $X_{1}^{*}>Q^{*}-X_{0}^{*}$ and $Z_{1}^{*}>0$.
} 
$U^{\prime}\left(W^{*}(S)\right)<\mathrm{E}_{1}\left[U^{\prime}\left(W^{*}(\tilde{S})\right)\right]$ for all $S \in(\hat{S}, \bar{S}]$. This implies

$$
\int_{\underline{S}}^{\bar{S}}\left\{U^{\prime}\left(W^{*}(S)\right)-\mathrm{E}_{1}\left[U^{\prime}\left(W^{*}(\tilde{S})\right)\right]\right\}(S-\hat{S}) \mathrm{d} H(S)<0
$$

where $H(S)$ is the distribution function of $\tilde{S}$, given the realization of $\tilde{f}_{1}$. As the left-hand side of inequality $(17)$ equals $\operatorname{cov}_{1}\left(U^{\prime}\left(\tilde{W}^{*}\right), \tilde{S}\right)$, the inequality contradicts the first-order condition for $X_{1}^{*}$ in (13).

Now suppose that $U^{\prime}\left(W^{*}(\bar{S})\right) \geq \mathrm{E}_{1}\left[U^{\prime}\left(W^{*}(\tilde{S})\right)\right]$. There has to be a unique point $\check{S} \in\left(\underline{S}, f_{1}\right)$ such that $U^{\prime}\left(W^{*}(S)\right)<\mathrm{E}_{1}\left[U^{\prime}\left(W^{*}(\tilde{S})\right)\right]$ for all $S \in[\underline{S}, \check{S})$ and $U^{\prime}\left(W^{*}(S)\right)>\mathrm{E}_{1}\left[U^{\prime}\left(W^{*}(\tilde{S})\right)\right]$ for all $S \in(\check{S}, \bar{S})$. It follows that

$$
\int_{\underline{S}}^{\bar{S}}\left\{U^{\prime}\left(W^{*}(S)\right)-\mathrm{E}_{1}\left[U^{\prime}\left(W^{*}(\tilde{S})\right]\right\}(S-\check{S}) \mathrm{d} H(S)>0,\right.
$$

again raising a contradiction to the first-order condition in (13). Hence, both $U^{\prime}\left(W^{*}(\underline{S})\right)$ and $U^{\prime}\left(W^{*}(\bar{S})\right)$ are strictly smaller than $\mathrm{E}_{1}\left[U^{\prime}\left(W^{*}(\tilde{S})\right)\right]$ such that there are two points where $U^{\prime}\left(W^{*}(S)\right)=\mathrm{E}_{1}\left[U^{\prime}\left(W^{*}(\tilde{S})\right)\right]$.

(d) Now, we resume the proof of Proposition 2. Suppose that $X_{1}^{*}>Q^{*}-X_{0}^{*}$ and $Z_{1}^{*}>0$ such that $\partial W^{*} / \partial S$ changes its sign as required by (13). Let $A=$ $\mathrm{E}_{1}\left[U^{\prime}\left(W^{*}(\tilde{S})\right) \mid \tilde{S}<f_{1}\right]$ and $B=\mathrm{E}_{1}\left[U^{\prime}\left(W^{*}(\tilde{S})\right) \mid \tilde{S}>f_{1}\right]^{24}$, where $\mathrm{E}_{1}[\cdot \mid \cdot \cdot]$ is the conditional expectation operator with respect to $H(S)$. There are two mutually exclusive cases: (i) $A>B$ and (ii) $A \leq B$. Consider case (i) first. Notice that

\footnotetext{
${ }^{24} \mathrm{E}_{1}\left[U^{\prime}\left(W^{*}(\tilde{S})\right]=A H\left(f_{1}\right)+B\left(1-H\left(f_{1}\right)\right)\right.$ by definition.
} 


$$
\begin{aligned}
& \operatorname{cov}_{1}\left(U^{\prime}\left(W^{*}(\tilde{S})\right), \max \left(\tilde{S}-f_{1}, 0\right)\right. \\
& =\int_{f_{1}}^{\bar{S}}\left\{U^{\prime}\left(W^{*}(S)\right)-\mathrm{E}_{1}\left[U^{\prime}\left(W^{*}(\tilde{S})\right)\right]\right\}\left(S-S_{2}\right) \mathrm{d} H(S) \\
& \quad+\int_{f_{1}}^{\bar{S}}\left\{U^{\prime}\left(W^{*}(S)\right)-\mathrm{E}_{1}\left[U^{\prime}\left(W^{*}(\tilde{S})\right)\right]\right\}\left(S_{2}-f_{1}\right) \mathrm{d} H(S) .
\end{aligned}
$$

It follows from Lemma 1 that the first term in (19) is negative. The second term in (19) is equal to $(B-A)\left(S_{2}-f_{1}\right) H\left(f_{1}\right)\left(1-H\left(f_{1}\right)\right)$. As $A>B, S_{2}>f_{1}$ and $0<$ $H\left(f_{1}\right)<1$, this term is negative as well. Hence, $\operatorname{cov}_{1}\left(U^{\prime}\left(W^{*}(\tilde{S})\right), \max \left(\tilde{S}-f_{1}, 0\right)\right)<0$ in case (i).

Now, consider case (ii). As $\tilde{S}-f_{1}=\max \left(\tilde{S}-f_{1}, 0\right)-\max \left(f_{1}-\tilde{S}, 0\right)$, condition (13) implies

$$
\begin{aligned}
& \operatorname{cov}_{1}\left(U^{\prime}\left(W^{*}(\tilde{S})\right), \max \left(\tilde{S}-f_{1}, 0\right)\right) \\
& =\operatorname{cov}_{1}\left(U^{\prime}\left(W^{*}(\tilde{S})\right), \max \left(f_{1}-\tilde{S}, 0\right)\right) \\
& =\int_{\underline{S}}^{f_{1}}\left\{U^{\prime}\left(W^{*}(S)\right)-\mathrm{E}_{1}\left[U^{\prime}\left(W^{*}(\tilde{S})\right)\right]\right\}\left(S_{1}-S\right) \mathrm{d} H(S) \\
& +\int_{\underline{S}}^{f_{1}}\left\{U^{\prime}\left(W^{*}(S)\right)-\mathrm{E}_{1}\left[U^{\prime}\left(W^{*}(\tilde{S})\right)\right]\right\}\left(f_{1}-S_{1}\right) \mathrm{d} H(S) .
\end{aligned}
$$

Lemma 1 implies that the first term in (20) is negative. The second term in (20) equals $(A-B)\left(f_{1}-S_{1}\right) H\left(f_{1}\right)\left(1-H\left(f_{1}\right)\right)$ which is non-positive since $A \leq B$, $S_{1}<f_{1}$ and $0<H\left(f_{1}\right)<1$. Hence, $\operatorname{cov}_{1}\left(U^{\prime}\left(W^{*}(\tilde{S})\right), \max \left(\tilde{S}-f_{1}, 0\right)\right)$ is negative in case (ii) as well.

This raises a contradiction to the optimality of $X_{1}^{*}>Q^{*}-X_{0}^{*}$ and $Z_{1}^{*}>0$ as the first-order condition for $Z_{1}^{*}$ requires $\operatorname{cov}_{1}\left(U^{\prime}\left(W^{*}(\tilde{S})\right), \max \left(\tilde{S}-f_{1}, 0\right)\right)$ to be zero in the case of (15) or to be positive in the case of (16). Hence, the optimal decision for $\kappa<0$ is given by $X_{1}^{*}<Q^{*}-X_{0}^{*}$ and $Z_{1}^{*}<0$. 